\title{
Cell Wall Growth and Modulation Dynamics in a Model Unicellular Green Alga_Penium margaritaceum: Live Cell Labeling with Monoclonal Antibodies
}

\author{
David S. Domozych, Hannah Brechka, Alicia Britton, and Marc Toso \\ Department of Biology and Skidmore Microscopy Imaging Center, Skidmore College, Saratoga Springs, New York, NY 12859, USA \\ Correspondence should be addressed to David S. Domozych, ddomoz@skidmore.edu
}

Received 15 June 2010; Accepted 9 January 2011

Academic Editor: Lee Meisel

Copyright (C) 2011 David S. Domozych et al. This is an open access article distributed under the Creative Commons Attribution License, which permits unrestricted use, distribution, and reproduction in any medium, provided the original work is properly cited.

Penium margaritaceum is a unicellular charophycean green alga that possesses cell wall polymers similar to those of land plants. Several wall macromolecules of this alga are recognized by monoclonal antibodies specific for wall polymer epitopes of land plants. Immunofluorescence protocols using these antibodies may be employed to label specific cell wall constituents of live cells. Fluorescent labeling persists for several days, and this attribute allows for tracing of wall epitopes in both long- and short-term studies of cell development. Quantitative analysis of surface area covered by cell wall polymers is also easily performed. We show that significant cell expansion caused by incubation of cells in low levels of osmotically active agents like mannitol, glucose, or sucrose results from the inability of cells to undergo cytokinesis but does not result in significant changes to the amount of new cell wall. We also demonstrate that cells can be maintained for long periods of time in culture medium supplemented with specific cell wall-degrading enzymes where notable changes to wall infrastructure occur. These results demonstrate the great potential value of Penium in elucidating fundamental events during cell wall synthesis and modulation in plant cells.

\section{Introduction}

The production of the cell wall is a profoundly important process of plant cell dynamics. The synthesis, secretion, positioning, and postsecretory modulation of the diverse set of cell wall macromolecules entail the coordinated interaction of multiple subcellular systems, the activation of cross-talking signal cascades, and responses to internal developmental programs and external biotic and abiotic stressors $[1,2]$. Additionally, cell wall polymers constitute major products of a plant's photosynthetic activity (e.g., $70 \%$ of all land plant biomass is cell wall material), and their syntheses are believed to be controlled by more than $15 \%$ of the plant's total genome $[3,4]$. The cell wall of actively growing plant cells, that is, the primary cell wall, is a complex mosaic of polymers whose structural foundation is a network of cellulose microfibrils that are tethered by hemicellulosic polymers. This microfibrillar complex is embedded in a matrix of pectins along with a variety of proteoglycans/proteins including arabinogalactan proteins (AGPs), extensin, expansin, and multiple enzymes [5]. Our understanding of cell primary wall structure and biochemistry has been greatly enhanced over the past decades by new technologies developed in molecular genetics, microscopy- and spectroscopy-based imaging, and immunobinding-based microarray techniques $[4,6,7]$. However, the precise mapping of specific wall polymers and their dynamic modulations within the cell wall during various phases of growth, development, and response to stressors remain incompletely resolved and constitute a major challenge in plant cell biology.

Pectins represent a major group of diverse, galacturonic acid- (galA-) containing, matrix polymers that play significant roles in cell/wall dynamics. Pectins have been shown to function in cell expansion, cell-cell adhesion, wall porosity, water retention, ion/growth factor/enzyme binding, and defense [8]. The most common pectic polymers are 
homogalacturonans (HGs) that possess a backbone of $\alpha$ 1,4-D-galA residues Varying degrees of methyl-esterification or $O$-acetylation of the galA residues directly influence the chemical and physical nature of an HG including its ability to bind to cations like calcium $\left(\mathrm{Ca}^{2+}\right)$ and form rigid gels. Other pectic polymers such as xylogalacturonans and the rhamnogalacturonans (RGs), RG-I and RG-II, represent polymers with complex oligosaccharide side chains attached to the HG backbone and/or with a heteroplymeric backbone (e.g., galA-rhamnose repeating units in RG-I). The genetic machinery involved in pectin synthesis is still poorly understood with at least 50 glycosyltransferases required for synthesis of the various pectic macromolecules $[9,10]$. HGs are synthesized in the cis cisternae of the Golgi Apparatus (GA), methylesterified in the medial cisternae, substituted in the trans cisternae, and carried to the plasma membrane in secretory vesicles [11]. HGs are thought to be secreted to the periplasmic space/cell wall in a highly methyl-esterified form. Here, they are de-esterified by pectin methylesterase (PME) that, in turn allows them to complex $\mathrm{Ca}^{2+}$ and form gels [12]. Once in the wall edifice, the displacement and chemical modification of the HGs and other pectins during cell morphogenesis are poorly resolved. This, in turn, hampers our understanding of the role of pectins in basic cell growth and development.

Penium margaritaceum is a unicellular member of the charophycean green algae or CGA (Streptophyta, Viridiplantae), that is, the extant group of green algae most closely allied to land plants $[13,14]$. This alga provides an attractive model system for studying pectic macromolecules and their processing in live cells. Penium grows/divides relatively quickly and only possesses a primary cell wall containing several of the polymers found in land plant cell walls [15] including an HG-rich outer wall layer that complexes $\mathrm{Ca}^{2+}$ to form a distinctive reticulated network. Live labeling of Penium with monoclonal antibodies (mAbs) that bind to epitopes of land plant HGs have demonstrated that HG is secreted in a narrow band in the center of the cell in a highly esterified form. Once secreted, the HG displaces the older cell wall complex outward toward each pole. During this process, the HG is de-esterified, presumably by a PME, and subsequently complexes with $\mathrm{Ca}^{2+}$ to yield the reticulated outer cell wall layer [16]. Live cell labeling of Penium affords multiple and exciting opportunities to examine both the qualitative and quantitative aspects of HG and wall dynamics during cell development and the effects of specific altering agents on wall synthesis. In this study, we demonstrate multiple ways that live cell labeling with fluorophore-conjugated antibodies with Penium may be used to dissect the complexities of cell wall development.

\section{Materials and Methods}

Penium margaritaceum (Clone\#8, Skidmore College Algal Culture Collection) was maintained on Woods Hole medium supplemented with $10 \%$ soil extract (WHS) and was grown under previously described conditions [15]. Cells were harvested for observation and experimentation approximately
4-7 days after subculturing. Cells were collected by centrifugation at $1,000 \times \mathrm{g}$ for $1 \mathrm{~min}$ on an IEC clinical centrifuge (Needham, MA, USA) and washed three times with fresh growth medium. Each washing included resuspension of the cell pellet with fresh growth media followed by $10 \mathrm{sec}$ of vortexing. The final washed pellet was first blocked with WHS containing $1 \%$ carnation instant milk for $30 \mathrm{~min}$, washed three times with WHS, and incubated in antibody solutions dissolved in WHS. For the mAbs, JIM5, LM18, JIM7, and JIM13 (Plant Probes, Leeds, UK), 1/10 dilutions were used while for anti-EPS polyclonal antibody (developed at Skidmore College [17]), the labeling dilution was 1/50. Cells were incubated at room temperature with constant shaking for $90 \mathrm{~min}$. Cells were then washed three times with WHS, blocked for $30 \mathrm{~min}$, washed three times, and then treated with goat antirat antibody-TRITC (for JIM5, LM18, JIM13, and JIM7) or goat anti-mouse-TRITC (for anti-EPS) at a $1 / 50$ dilution for $90 \mathrm{~min}$ at room temperature. The cells were then washed three times with WHS and viewed for microscopy or placed in experimental treatments. For labeling of nuclei, cells were labeled with $1 \mu \mathrm{g} / \mathrm{mL}$ of SYTO 9 (Invitrogen, Carlsbad, CA, USA) for 5 min followed by three washes with WHS. For fluorescence light microscopy (FLM), an Olympus BX-60 light microscope (LM) equipped with a DP-70 digital camera was used. For confocal laser scanning microscopy (CLSM), an Olympus BX-61 LM equipped with a Fluoview 300 confocal unit was employed.

For single cell studies, individual labeled cells were isolated using a pulled capillary tube and then deposited individually into $200 \mu \mathrm{L}$ of fresh WHS in a well of 96-welled microplates. The plates were placed in growth chambers with low light levels (100 lux), control or normal light levels (3,000 lux), or high light levels (5,400 lux). Additionally, some cells were incubated in medium adjusted to $\mathrm{pH} 5.5$ or $\mathrm{pH} 9$ or supplemented with sucrose, glucose, and mannitol to $3 \%-4 \%$.

For quantitative studies, labeled cells were placed in $5 \mathrm{~mL}$ of WHS with varying concentrations of mannitol, glucose, and sucrose in 6-welled petridishes and cultured as above. After $48 \mathrm{~h}$, aliquots of cells from each treatment were collected by centrifugation and viewed by FLM. At least 50 cells per each treatment were photographed. Total cell length and new cell wall growth as determined by nonlabeled areas were digitally measured, and surface area (SA) measurements were determined (see Section 3).

For long-term enzyme incubation studies, $200 \mu \mathrm{g} / \mathrm{mL}$ solutions of cellulase (Sigma C1184, St. Louis, MO, USA) or pectinase (Sigma P-2401) were dissolved in growth medium, and $\mathrm{pH}$ was adjusted to that of normal WHS ( $\mathrm{pH}$ 7.2). The enzyme solution was then filter sterilized before the addition of JIM5-labeled cells. Microscopy-based observations were made $48-72 \mathrm{~h}$ later.

\section{Results}

3.1. General. Penium margaritaceum has proven to be a valuable model organism for monitoring cell wall macromolecules and their modulation during cell development. 


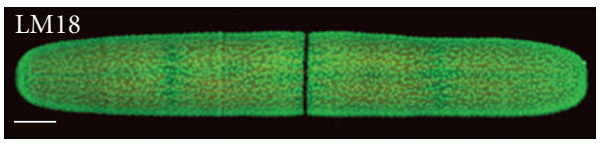

(a)

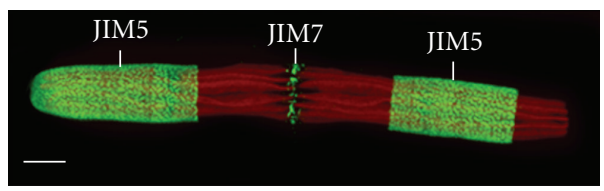

(c)

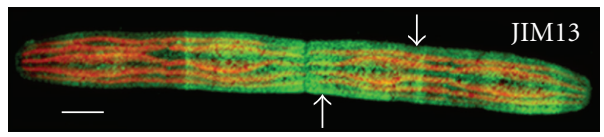

(e)

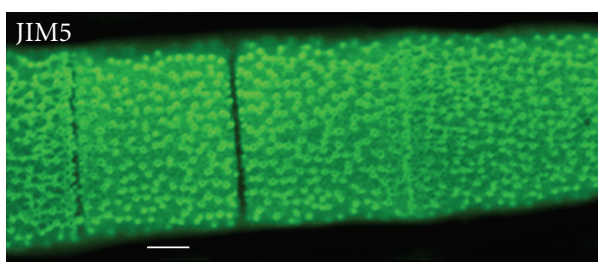

(b)

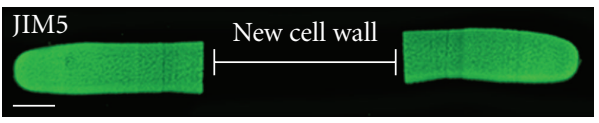

(d)

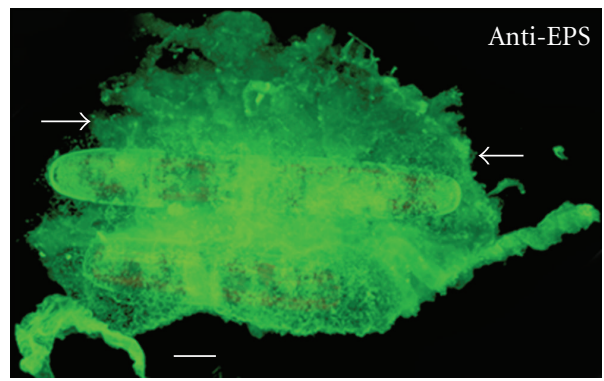

(f)

FIGURE 1: Live cell labels. (a) represents a cell labeled with the HG-specific mAb, LM18. Note the punctate appearance of the HGs on the wall surface. Scale bar $=10 \mu \mathrm{m}$. (b) is a magnified view of the HG lattice, labeled with JIM5, on the outer portion of the cell. Scale bar $=4.75 \mu \mathrm{m}$. (c) represents a cell first labeled with JIM5, recultured for $24 \mathrm{~h}$, and then relabeled with JIM7. Scale bar $=14.8 \mu \mathrm{m}$. (d) represents a cell labeled with JIM5 and recultured for $24 \mathrm{~h}$. The dark zone in the center represents where HGs are secreted. (e) is a cell labeled with the AGP-binding $\mathrm{mAb}$, JIM13. A finely labeled sheath made of numerous puncta is labeled on the outer wall surface (arrows). Scale bar $=14.8 \mu \mathrm{m}$. (f) is cell labeled with an anti-EPS antibody and highlights the extensive sheath that surrounds the cell (arrows). Scale bar $=14.8 \mu \mathrm{m}$.

Several mAbs raised against land plant wall polymers label specific components of the Penium wall. As important, labeled cells can be returned to culture, and patterns of wall development may be subsequently analyzed. The fluorescent signal of the labeling used for FLM and CLSM persists for several days and allows for temporal tracing of specific macromolecules under specific experimental conditions. CLSM imaging of cells (Figure 1) labeled with LM18 or JIM5, mAbs that bind to HGs with relatively low levels of methyl esterification [18], highlights the distinct HG lattice found in the outer wall layer (Figures 1(a) and 1(b)). This lattice is distinguished by a network of projections raised above the wall surface also see [15]. When comparable 3-dimensional (3D) scans are made of the two large chloroplasts which fill the lumen of the cell and are combined with 3D scans of the labeled cell wall, the relationship of the cell wall to the entire cell volume is conveniently observed (Figures 1(a), 1(c) and 1(e)). Additionally, mAb colabeling allows for the elucidation of the structural positioning of different macromolecules during precise time sequences. For example, Figure 1(c) highlights a cell labeled with JIM5, recultured for $36 \mathrm{~h}$, and then labeled with JIM7, an mAb that binds to HGs with relatively high levels of methyl esterification. Perhaps the most valuable aspect of this live labeling is the ability to recognize and measure new wall growth. When pectins are labeled with an $\mathrm{mAb}$ and the cells are recultured, new wall zones appear as unlabeled or darkened regions in micrographs (Figures 1(c) and 1(d)). These unlabeled zones provide important information on both the qualitative and quantitative aspects of cell wall development (see below). While HGs are dominant polymers of the cell wall of Penium, other wall components can also be monitored via live cell labeling. This includes the AGP epitope recognized by the mAb, JIM13 (Figure 1(e)) that forms a loose punctate coating on the cell wall surface. Additionally, an antibody raised against the extracellular polymeric substance or EPS of this alga [17] labels an extensive sheath found outside the cell wall Figure 1(f).

3.2. Single Cell Labeling. Single mAb-labeled cells may be isolated and monitored over various periods of time. This technique allows for tracing of the developmental history of specific cell wall macromolecules directly in one cell. Figure 2 illustrates normal wall development versus cells grown under different experimental conditions. Under low light, wall expansion is severely curtailed while under high light, wall development results in asymmetric deposition of the pectin see also [16]. Wall expansion is not impaired in 
TABLE 1: Surface areas of the cell wall under various experimental treatments. All figures are in $\mu \mathrm{m}^{2}$. For each category, at least 50 cells were measured after $48 \mathrm{~h}$ incubation.

\begin{tabular}{|c|c|c|c|}
\hline Experimental treatment & SA of whole cell & SA of new wall zone (JIM5 label) & $\%$ of new wall SA to total cell SA \\
\hline Control & $8,600 \pm 200$ & $4,100 \pm 200$ & $47.6 \pm 2.3$ \\
\hline $3 \%$ glucose & $15,400 \pm 200$ & $7.100 \pm 200$ & $46.1 \pm 1.3$ \\
\hline $4 \%$ glucose & $15,100 \pm 200$ & $6,600 \pm 200$ & $43.7 \pm 1.3$ \\
\hline $3 \%$ mannitol & $13,300 \pm 200$ & $5,850 \pm 200$ & $43.9 \pm 1.5$ \\
\hline $4 \%$ mannitol & $16,500 \pm 200$ & $7,425 \pm 200$ & $45.0 \pm 1.2$ \\
\hline $3 \%$ sucrose & $14,700 \pm 200$ & $6,300 \pm 200$ & $42.8 \pm 1.4$ \\
\hline $4 \%$ sucrose & $17,000 \pm 200$ & $8,200 \pm 200$ & $48.2 \pm 1.2$ \\
\hline
\end{tabular}

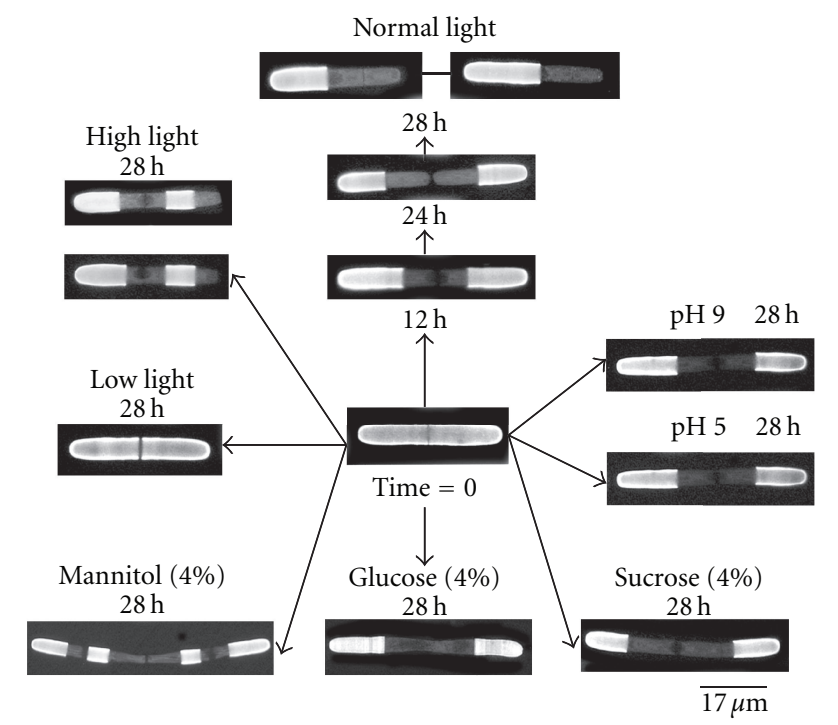

FIGURE 2: Live cell labeling (JIM5) of single cells incubated under different experimental conditions. Except for cells grown normal light conditions (3,000 lux), the images of the other cells were from $28 \mathrm{~h}$ cultures. Low light conditions (100 lux) produced virtually no wall expansion while high light (5,400 lux) produced cells with asymmetric labeling patterns. Incubation of cells in medium adjusted to $\mathrm{pH} 5$ or pH 9 resulted in little alteration to cell expansion. Cells incubated in $4 \%$ mannitol, glucose, or sucrose resulted in significant cell expansion.

cells grown in media adjusted to $\mathrm{pH} 9$ or 5 . However, cells grown in $4 \%$ solutions of mannitol, glucose, or sucrose show significant expansion patterns.

3.3. Quantitative Analysis. Live cell labeling of Penium also allows for quantitative analysis of wall/macromolecule processing during cell development. The measurement of new cell wall zones and total cell length are taken after specific periods of time under various experimental conditions. It is important to note that under certain culture conditions such as high light, two new wall zones may be found on an individual cell instead of one [16]. The lengths of each of these zones are measured and then added together for ascertaining new wall growth. The cell diameter of Penium margaritaceum is consistent over most of its length (i.e., $17 \mu \mathrm{m}$ ) except for the bluntly rounded poles. These measurements provide the necessary data for determining the surface area (SA) measurement using the basic SA formula developed for cylinders: $\mathrm{SA}=2\left(\pi \times r^{2}\right)+(2 \pi \times r)$ times $L$ (where $r=$ radius of cell, $L=$ length of new wall regions or length of cell). In our work with Penium, we also factored in a 0.98 (SA) curvature factor to take into account the rounding of the poles. This was calculated by assessing cell diameter across the entire length of ten randomly selected cells.

Our calculations allowed for the determination of the SA covered by new HG/cell wall material and more importantly the ratio of new cell wall SA to total cell SA. For example, in this study, we incubated labeled cells in low concentrations of exogenous sugars (i.e., to monitor the effects of osmotic conditions on cell/wall growth) and measured these values after $48 \mathrm{~h}$. We then measured the length of the cells and new cell wall regions in at least 50 cells per treatment. Results can be seen in Table 1. Interestingly, we noted that while the length of treated cells increases dramatically, the actual percentage of new wall on whole cell surface area was similar to normal treated cells. Images of cells treated with the different sugars can be seen in Figure 3. In these samples, we also wanted to monitor the cell cycle stage of treated cells and used the dye, SYTO9, to label the nuclei. In many of the expanded cells, two nuclei were found per cell. 


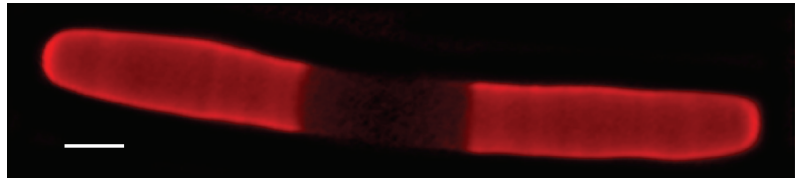

(a)

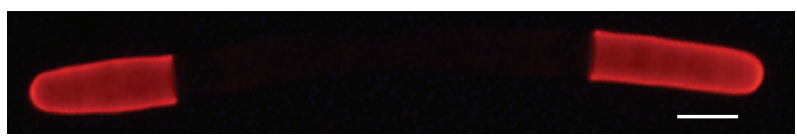

(c)

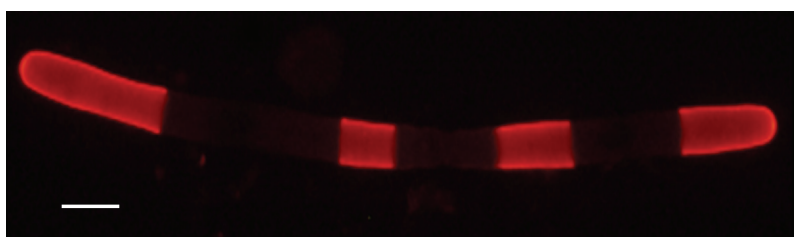

(e)

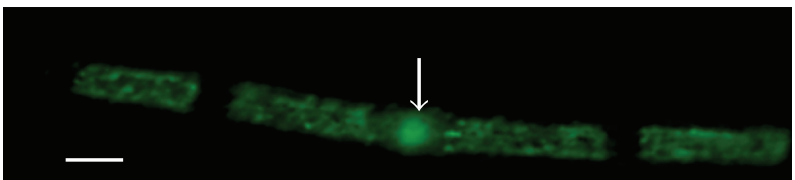

(b)

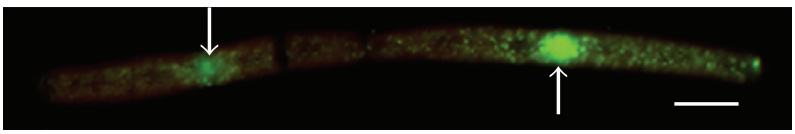

(d)

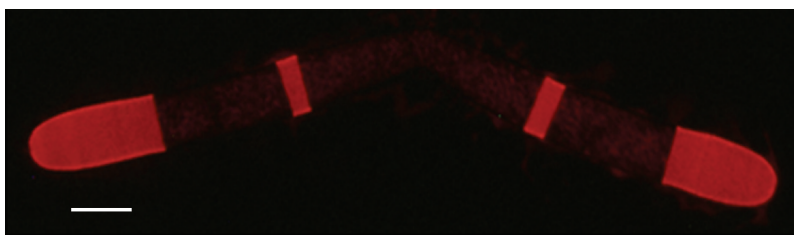

(f)

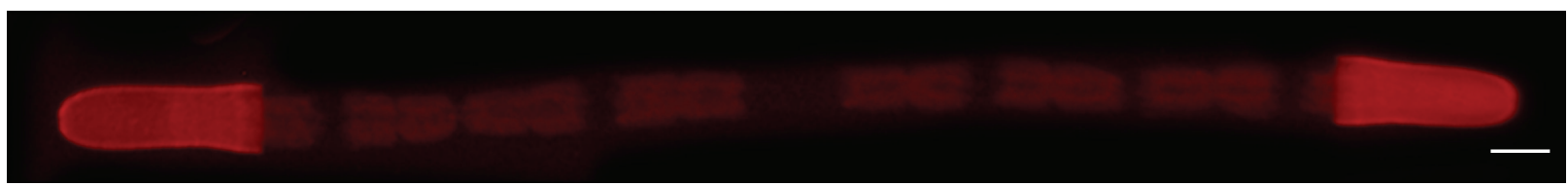

$(\mathrm{g})$

Figure 3: The effects of low levels of sugars upon cell growth. (a) represents a control cell $48 \mathrm{~h}$ after labeling with JIM5. New HG secretion/wall growth is the dark or unlabeled zone in the cell center. Scale bar $=10.2 \mu \mathrm{m}$. (b) is the cell in (a) labeled with SYTO9 and highlights the nucleus (arrow). Scale bar $=10 \mu \mathrm{m}$. (c) represents a cell treated in $4 \%$ mannitol for $48 \mathrm{~h}$. This cell is greatly expanded, Scale bar $=16 \mu \mathrm{m}$. (d) is the cell in (c) labeled with SYTO9 and highlights the two nuclei (arrows). Scale bar $=16 \mu \mathrm{m}$. (e) is a cell after $48 \mathrm{~h}$ in $4 \%$ mannitol. Scale bar $=20 \mu \mathrm{m}$. (f) is a cell after $48 \%$ in $4 \%$ glucose. Scale bar $=17 \mu \mathrm{m}$. (g) is a cell after $48 \mathrm{~h}$ in $4 \%$ sucrose. Scale bar $=18 \mu \mathrm{m}$. Figures 4(c), 4(e), 4(f), and 4(g) are labeled with JIM5, and all images were acquired using FLM.

3.4. Treatment of Cells in Wall-Degrading Enzymes. An experiment to study the effects of exogenous cell walldegrading enzymes on cell/wall growth and development was undertaken in this study. Cells were first incubated in either $200 \mu \mathrm{g} / \mathrm{mL}$ of cellulase or $200 \mu \mathrm{g} / \mathrm{mL}$ of pectinase. After 24 and $72 \mathrm{~h}$, cells were collected and labeled with JIM5 (Figure 4). In cellulose-treated cells, enhanced JIM5 labeling of the wall was noted in the cell center or isthmus region (Figures 4(a) and 4(b)). Cell morphology was also altered in this region and cell division yielded daughter cells with "knob-" like ends (Figure 4(c)). These knobs also produced brightly fluorescent zones (Figure $4(\mathrm{~d})$ ). In pectinase-treated cells, nonlabeled bands were often observed along the cell wall (Figure 4(e)). Under these conditions, cells continued to grow and divide. The cell wall surface of the expanding semicell of new daughter cells produced irregular JIM5labeling patterns (Figure 4(f)). These cells though remained alive as noted by dual labeling to highlight both cell wall and chloroplast fluorescence (Figure $4(\mathrm{~g})$ ). Cells remained viable in these enzyme solutions for up to two weeks.

\section{Discussion}

Geographically accurate mapping of specific cell wall polymers is critical to our understanding of the modulations that occur in the plant cell wall during cell and tissue development. Recent research has clearly demonstrated that the cell wall is a dynamic system that frequently changes in biochemistry and microarchitecture as a response to internal developmental cues and external environmental stressors [7]. With the exception of very specialized plant cells like growing pollen tubes or tissue culture cells, there has been a paucity of information concerning wall dynamics in individual live plant cells as most studies have focused upon multicellular plants. Often, many of these studies have required fixation and subsequent sectioning for microscopy-based analyses due to the inability of wall antibodies to penetrate the interior of complex tissues in live plants. While these studies have produced valuable results, they are limited in that there is a possible loss of significant information that occurs during the aforementioned processing of specimens. Likewise, the identification of specific wall structures and functions of individual cells in complex tissues is limited.

CGA offer exciting possibilities for studying cell wall dynamics. Recently, new data has emerged demonstrating that many species of the CGA possess cell wall polymers similar to that of land plants [19-21]. CGA are also much simpler in morphological design than land plants, and many taxa are unicellular like Penium margaritaceum. Penium offers significant experimental attributes that make 


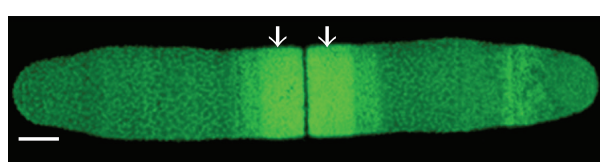

(a)

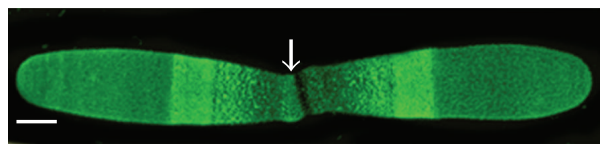

(c)

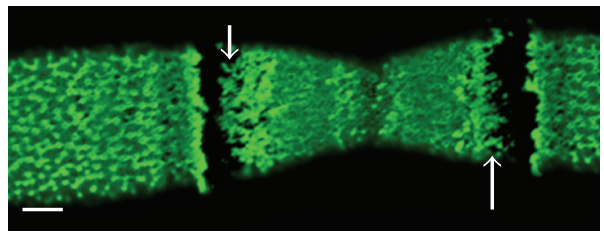

(e)

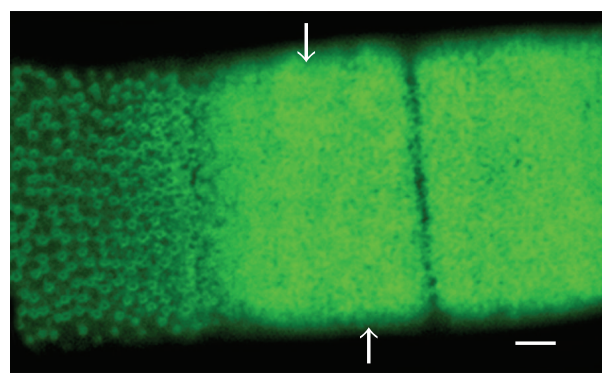

(b)

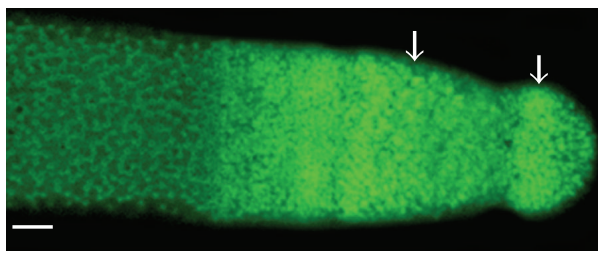

(d)

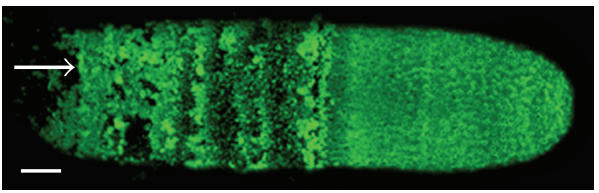

(f)

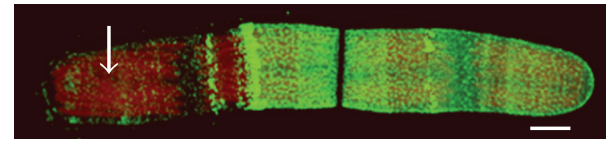

(g)

FIGURE 4: Cells incubated in cell wall-degrading enzymes. (a) represents a cell incubated in $200 \mu \mathrm{L} / \mathrm{mL}$ of cellulase for $48 \mathrm{~h}$ and then labeled with JIM5. Note the intense labeling (arrows) in the cell center. Scale bar $=7.8 \mu \mathrm{m}$. (b) is a magnified view of the JIM5-labeled zone in a cell incubated in cellulase. While the intensity of labeling is greater than surrounding zones, the typical HG lattice is not apparent (arrows). Scale bar $=2.5 \mu \mathrm{m}$. (c) shows a predivision phase of cell incubated in cellulase for $72 \mathrm{~h}$. In addition to the intense JIM5 labeling, the morphology of the cell center (arrow) changes forming a small "knob-" like structure. Scale bar $=8.5 \mu \mathrm{m}$. (d) highlights the new semicell of a daughter cell after cell division $(72 \mathrm{~h})$. Note the knob-like appearance of one pole of the cell and the intense JIM5 labeling (arrows). Scale bar $=3.8 \mu \mathrm{m}$. (e) is a profile of a cell incubated for $72 \mathrm{~h}$ in $200 \mu \mathrm{g} / \mathrm{mL}$ pectinase. Note the lack of labeling two bands on the cell (arrows). Scale bar $=4.4 \mu \mathrm{m}$. (f) is a recently divided cell incubated in pectinase. Note that the HG in the new semicell (arrow) is highly disorganized. Scale bar $=3.9 \mu \mathrm{m}$. $(\mathrm{g})$ is a recently divided cell labeled with JIM5 and overlayed with chloroplast scan. Note the lack of labeling in the wall of the new semicell (arrow). Cells could be kept alive for up to two weeks in these enzyme solutions. Scale bar $=7.8 \mu \mathrm{m}$.

it a valuable model organism for studying live cell wall dynamics. In addition to possessing wall polymers similar to land plants $[15,16]$, this alga only produces a primary wall, can be easily grown in large synchronous cultures or precisely defined experimental conditions, and most importantly can be live labeled with fluorescent mAbs. The $\mathrm{mAb}$ label remains in the wall and its displacement during growth and development can be accurately traced. In this study, we demonstrate the utility of Penium in single-cell studies, quantitative wall analyses, and experimental testing. Though we focused primarily on an mAb that binds to HGs, JIM5, other mAbs bind to the wall and offer exciting possibilities for future studies.

In this study, the effects of exogenous sugars on cell development and $\mathrm{HG} /$ wall production were monitored.
We chose the three sugars, glucose, sucrose, and mannitol because they have been successfully used in our laboratory to make protoplasts from Penium. 3\%-4\% concentrations were selected because they did not cause significant plasmolysis of the protoplast nor lead to the formation of Hechtian strands. The most obvious effect on cells was the notable expansion of the cells (Figure 3 ). When these cells were labeled with SYTO9, two nuclei were found per cell and in the position expected after cell division. That is, the nuclei were located in the midcell regions of the incompletely divided daughter cells. This indicated that mitosis and postmitotic repositioning of daughter nuclei had occurred. When we calculated percentage of surface area covered by new HG/wall material in relation to total cell SA (Table 1), the results were approximately the same as untreated cells. These observations clearly 
indicated that the cytokinetic mechanism was affected by the treatments, but the formation of new wall material was not. Interestingly, if treated cells were placed back into fresh growth medium up to $72 \mathrm{~h}$, cytokinesis ultimately occurred (pers. obs.). The effects of osmotically active agents on cell/tissue development in plants, wall integrity, the cytoskeletal system, and cytokinetic mechanism have been well documented in plants and yeast [22-28]. We might postulate that the hyperosmotic conditions in Penium affected parts of, but not all of, the cell's cytoskeletal system. For example, the microtubule network involved in mitosis and for repositioning daughter nuclei was not affected. However, the microtubule/microfilament networks responsible for cytokinesis, and specifically new cross wall formation that separates daughter cells, were affected. These results correspond with previous work whereby treatment with the actin-affecting agent, cytochalasin $\mathrm{E}$, caused the development of filamentous division products [16]. Future work will be needed to elucidate the detailed connection between cytokinetic plate formation and the actin network in Penium. In particular, the use of GFP constructs that highlight the cytoskeletal network in live cells, when coupled with the live cell wall labeling protocols shown here, would greatly enhance our understanding of the dynamics of wall production during cell expansion and development. To date though, stable transformed Penium has yet to be accomplished.

We also studied the effects of long-term incubation of cells in cellulolytic or pectinolytic enzymes (Figure 4). Our goal was to monitor the cell wall structure and cell development under these conditions. After incubation with cellulase, the amount of HG, based on intense JIM5 labeling, increased significantly in the cell's midzone, that is, the region where new wall materials are added. Likewise, daughter cell products in this treatment expressed notable morphological alterations as well as intense JIM5 labeling in the active growth zone, that is, the expanding polar zone of a daughter cell. We suggest that the enhanced JIM5 labeling represents an increased production of HG in growth zones of affected cells to compensate for the loss of cellulose caused by enzymatic treatment. This might be similar to other plant systems whereby a decrease of one polymer type in the wall resulted in the enhanced production of other polymers to growth zones as well as morphological changes [29]. This "overcompensation" of other wall polymers most likely is a way of coping with conditions that alter wall integrity. The unusual knob-like morphology found at the growing pole of daughter cells may represent the morphological manifestation of altered expansion geometry at the active growth zone when cellulose processing is compromised in cells treated with cellulase. In cells incubated in parallel experiments using pectinase, this overcompensation phenomenon was not observed. Rather, the HG layers of the wall were partially digested, and cell growth and morphogenesis appeared unaffected. Future work will be needed to elucidate how an incomplete HG layer functions in the structural integrity of the cell wall.

Live cell labeling with fluorophore-conjugated mAbs represents a powerful tool in dissecting cell wall polymer processing during plant growth and development. The use of a unicellular plant system like Penium offers intriguing possibilities for future dissection of wall growth patterns in individual live cells. Future syntheses of other technologies from molecular genetics to biochemistry with this live-cell labeling will provide detailed portraits of wall dynamics in green plants.

\section{Acknowledgments}

The authors would like to thank Korena Burgio, Carly Sacks, and Pia Ruisi-Besares for their help on this project. This work was supported by a Grant form NSF-MCB (no. 0919925) to D. S. Domozych.

\section{References}

[1] O. Lerouxel, D. M. Cavalier, A. H. Liepman, and K. Keegstra, "Biosynthesis of plant cell wall polysaccharides-a complex process," Current Opinion in Plant Biology, vol. 9, no. 6, pp. 621-630, 2006.

[2] D. A. Geisler, A. Sampathkumar, M. Mutwil, and S. Persson, "Laying down the bricks: logistic aspects of cell wall biosynthesis," Current Opinion in Plant Biology, vol. 11, no. 6, pp. 647652, 2008.

[3] M. Pauly and K. Keegstra, "Cell-wall carbohydrates and their modification as a resource for biofuels," Plant Journal, vol. 54, no. 4, pp. 559-568, 2008.

[4] M. C. McCann, M. Defernez, B. R. Urbanowicz et al., "Neural network analyses of infrared spectra for classifying cell wall architectures," Plant Physiology, vol. 143, no. 3, pp. 1314-1326, 2007.

[5] N. Carpita and M. McCann, "The cell wall," in Biochemistry and Molecular Biology of Plants, B. B. Buchanan, W. Gruissem, and R. L. Jones, Eds., pp. 52-108, American Society of Plant Physiologists, Rockville, Md, USA, 2000.

[6] I. Moller, S. E. Marcus, A. Haeger et al., "High-throughput screening of monoclonal antibodies against plant cell wall glycans by hierarchical clustering of their carbohydrate microarray binding profiles," Glycoconjugate Journal, vol. 25, no. 1, pp. 37-48, 2008.

[7] P. Sarkar, E. Bosneaga, and M. Auer, "Plant cell walls throughout evolution: towards a molecular understanding of their design principles," Journal of Experimental Botany, vol. 60, no. 13, pp. 3615-3635, 2009.

[8] G. B. Seymour and J. P. Knox, "The chemical structure of pectins," in Pectins and Their Manipulation, G. B. Seymour and J. P. Knox, Eds., pp. 1-32, John Wiley \& Sons, New York, NY, USA, 2002.

[9] J. Harholt, A. Suttangkakul, and H. V. Scheller, "Biosynthesis of pectin," Plant Physiology, vol. 153, no. 2, pp. 384-395, 2010.

[10] A. Bacic, "Breaking an impasse in pectin biosynthesis," Proceedings of the National Academy of Sciences of the United States of America, vol. 103, no. 15, pp. 5639-5640, 2006.

[11] D. Mohnen, "Pectin structure and biosynthesis," Current Opinion in Plant Biology, vol. 11, no. 3, pp. 266-277, 2008.

[12] S. Wolf, G. Mouille, and J. Pelloux, "Homogalacturonan methyl-esterification and plant development," Molecular Plant, vol. 2, no. 5, pp. 851-860, 2009.

[13] L. A. Lewis and R. M. McCourt, "Green algae and the origin of land plants," American Journal of Botany, vol. 91, no. 10, pp. 1535-1556, 2004. 
[14] B. Becker and B. Marin, "Streptophyte algae and the origin of embryophytes," Annals of Botany, vol. 103, no. 7, pp. 9991004, 2009.

[15] D. S. Domozych, A. Serfis, S. N. Kiemle, and M. R. Gretz, "The structure and biochemistry of charophycean cell walls: I. Pectins of Penium margaritaceum," Protoplasma, vol. 230, no. 1-2, pp. 99-115, 2007.

[16] D. S. Domozych, L. Lambiasse, S. N. Kiemle, and M. R. Gretz, "Cell-wall development and bipolar growth in the desmid Penium margaritaceum (zygnematophyceae, streptophyta). Asymmetry in a symmetric world," Journal of Phycology, vol. 45, no. 4, pp. 879-893, 2009.

[17] D. S. Domozych, S. Kort, S. Benton, and T. Yu, "The extracellular polymeric substance of the green alga Penium margaritaceum and its role in biofilm formation," Biofilms, vol. 2, no. 2, pp. 129-144, 2005.

[18] Y. Verhertbruggen, S. E. Marcus, A. Haeger, J. J. Ordaz-Ortiz, and J. P. Knox, "An extended set of monoclonal antibodies to pectic homogalacturonan," Carbohydrate Research, vol. 344, no. 14, pp. 1858-1862, 2009.

[19] Z. A. Popper and S. C. Fry, "Primary cell wall composition of bryophytes and charophytes," Annals of Botany, vol. 91, no. 1, pp. 1-12, 2003.

[20] Z. A. Popper, "Evolution and diversity of green plant cell walls," Current Opinion in Plant Biology, vol. 11, no. 3, pp. 286 292, 2008.

[21] I. Sørensen, D. Domozych, and W. G. T. Willats, "How have plant cell walls evolved?" Plant Physiology, vol. 153, no. 2, pp. 366-372, 2010.

[22] T. Hamann, M. Bennett, J. Mansfield, and C. Somerville, "Identification of cell-wall stress as a hexose-dependent and osmosensitive regulator of plant responses," Plant Journal, vol. 57, no. 6, pp. 1015-1026, 2009.

[23] R. D. de Castro, A. A. M. van Lammeren, S. P. C. Groot, R. J. Bino, and H. W. M. Hilhorst, "Cell division and subsequent radicle protrusion in tomato seeds are inhibited by osmotic stress but DNA synthesis and formation of microtubular cytoskeleton are not," Plant Physiology, vol. 122, no. 2, pp. 327$335,2000$.

[24] M. J. Affenzeller, A. Darehshouri, A. Andosch, C. Lütz, and U. Lütz-Meindl, "Salt stress-induced cell death in the unicellular green alga Micrasterias denticulata," Journal of Experimental Botany, vol. 60, no. 3, pp. 939-954, 2009.

[25] K. Ueda and S. Yoshioka, "Cell wall development of Micrasterias americana, especially in isotonic and hypertonic solutions," Journal of Cell Science, vol. 21, no. 3, pp. 617-631, 1976.

[26] G. Komis, P. Apostolakos, and B. Galatis, "Hyperosmotic stress-induced actin filament reorganization in leaf cells of Chlorophyton comosum," Journal of Experimental Botany, vol. 53, no. 375, pp. 1699-1710, 2002.

[27] T. E. Proseus and J. S. Boyer, "Periplasm turgor pressure controls wall deposition and assembly in growing Chara corallina cells," Annals of Botany, vol. 98, no. 1, pp. 93-105, 2006.

[28] A. M. Robertson and I. M. Hagan, "Stress-regulated kinase pathways in the recovery tip growth and microtubule dynamics following osmotic stress in S. pombe," Journal of Cell Science, vol. 121, no. 24, pp. 4055-4068, 2008.

[29] I. W. Manfield, C. Orfila, L. McCartney et al., "Novel cell wall architecture of isoxaben-habituated Arabidopsis suspensioncultured cells: global transcript profiling and cellular analysis," Plant Journal, vol. 40, no. 2, pp. 260-275, 2004. 

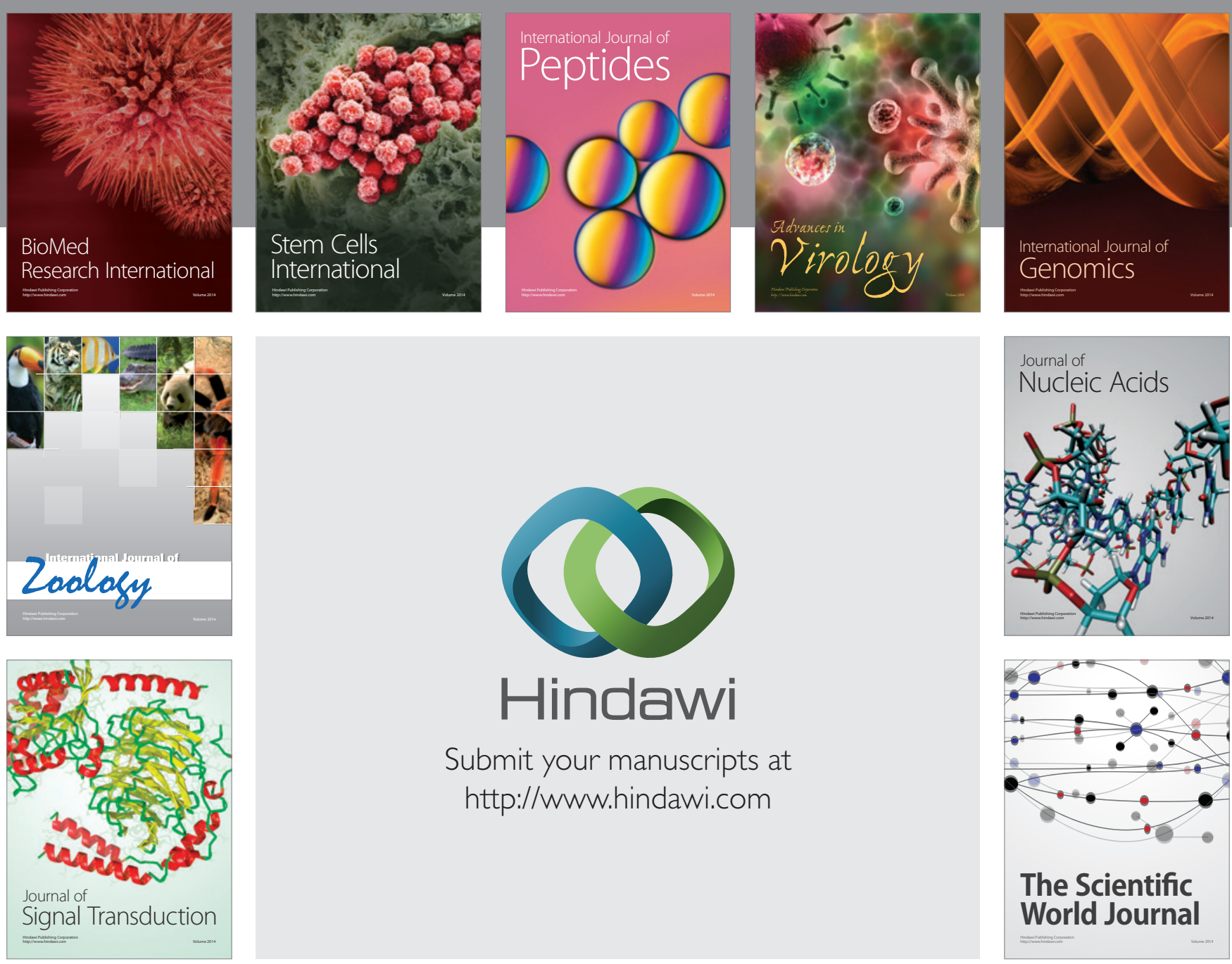

Submit your manuscripts at

http://www.hindawi.com
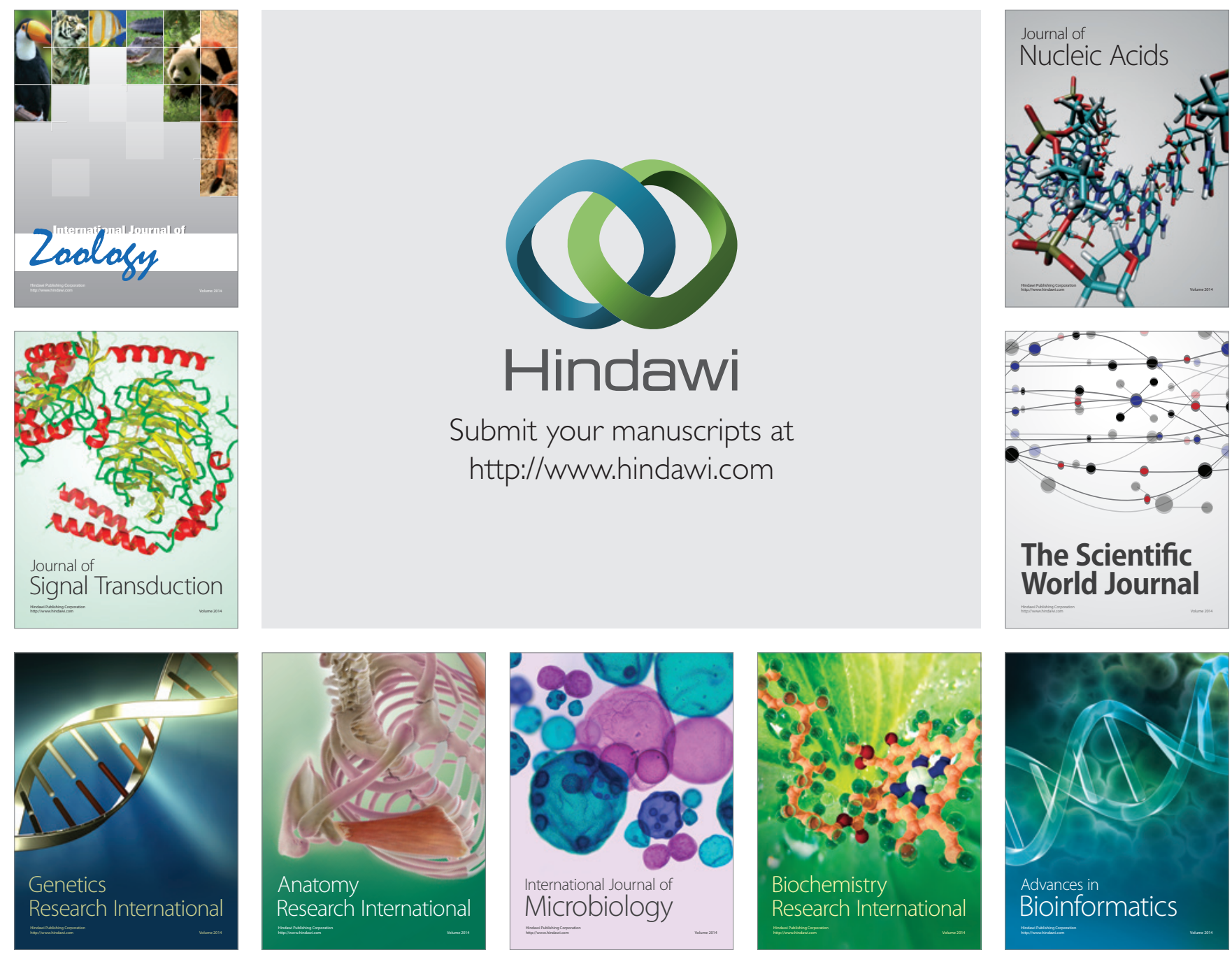

The Scientific World Journal
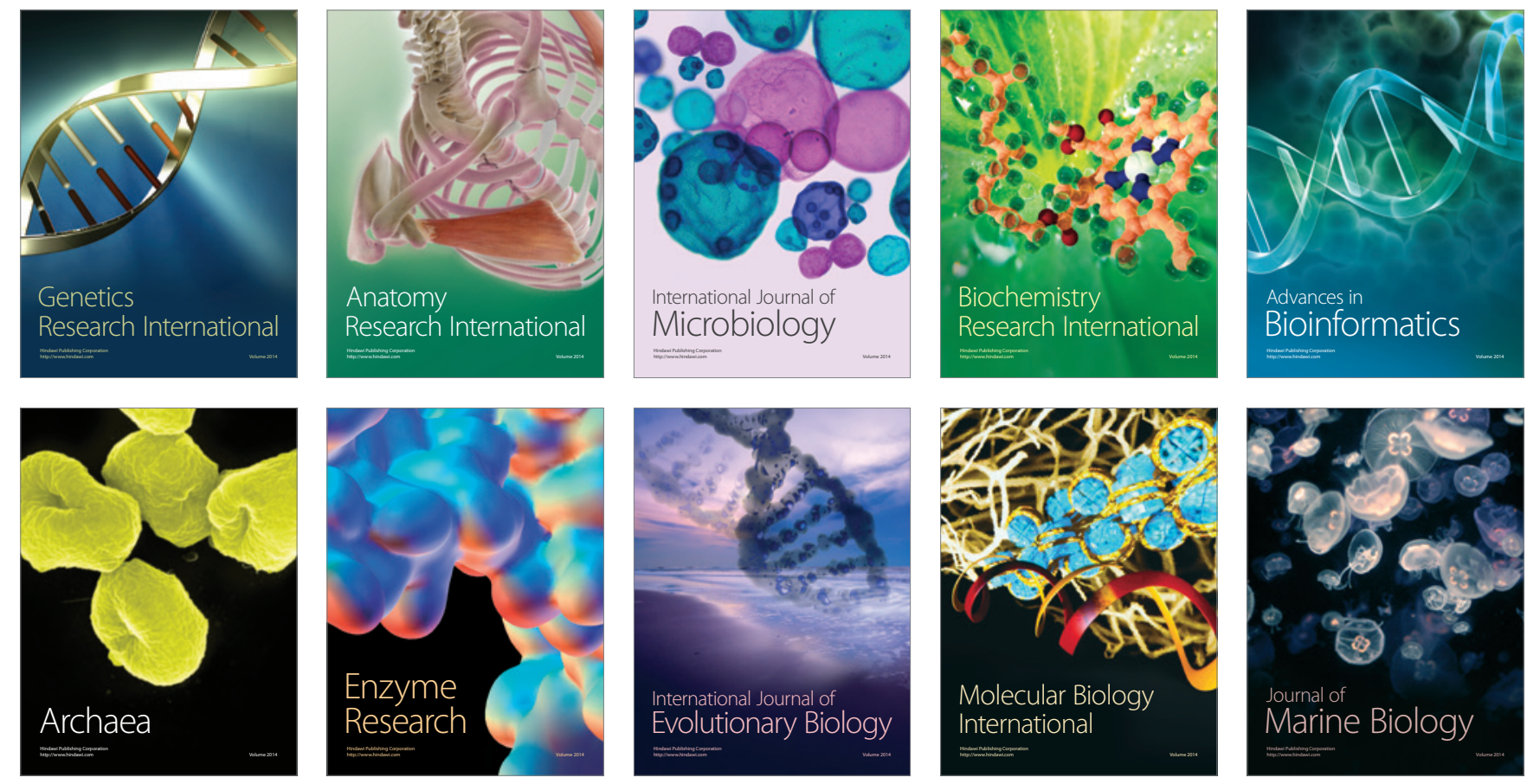